\title{
Developing a Knowledge Management System Using an Ontological Approach in Global Organization
}

\author{
Seung-Hwa Chung ${ }^{1}$, Simon Robertson ${ }^{1}$, Andre Minnaar ${ }^{1}$, \\ Mark Cook ${ }^{1}$, and Lily Sun ${ }^{2}$ \\ ${ }^{1}$ United Bible Societies, UK \\ schung@biblesocieties.org \\ ${ }^{2}$ University of Reading, UK \\ lily.sunereading.ac.uk
}

\begin{abstract}
This paper introduces an ontology-based knowledge model for knowledge management. This model can facilitate knowledge discovery that provides users with insight for decision making. The users requiring the insight normally play different roles with different requirements in an organization. To meet the requirements, insights are created by purposely aggregated transactional data. This involves a semantic data integration process. In this paper, we present a knowledge management system which is capable of representing knowledge requirements in a domain context and enabling the semantic data integration through ontology modeling. The knowledge domain context of United Bible Societies is used to illustrate the features of the knowledge management capabilities.
\end{abstract}

Keywords: Knowledge management system, Knowledge model, Ontology, Global organization.

\section{Introduction}

Knowledge management acquires information from multiple resources and uses the acquired information to generate value for an organization [1]. For a knowledge management system, there is a need to integrate an increasing set of diverse devices and information systems within an enterprise [2], e.g. inventory tracking systems, sales systems, finance systems, human resource systems, and so on, to effectively share the organizational knowledge [3]. Typically these devices and information systems are produced by a variety of developers with different data schemas. The information integration of such heterogeneous data using traditional data integration [4], which offers uniform access to a set of data sources through a mediated schema [5], is a specialist and brittle process, such that changing the structure of just one data source can force an integration redesign [6]. Data integration without involving semantics limits the data use to pre-defined functions, which are implemented by a rigorously agreed specification with the pre-defined meaning of terms for the exchange of data. 
This makes it difficult to manipulate the data according to the users' needs and to extract reasoned information from the data. Adding semantics to the data avoids these difficulties [7]. OWL (Web Ontology Language) is a well-known technology that enables semantics to be encoded with the data [8]. This technology formally represents the meaning involved in information (in other words, an ontology that specifies concepts and describes relationships between things and categories of things). The ontological approach to build a knowledge model offers significant advantages on sharing and generating value of the information for it enables the reasoning over data and handles the data exchange and integration for more flexibly.

There have been several investigations in this research field [9]. The data integration research trend is moving toward semantic data integration using ontology due to it having the capability of specifying relationships between concepts and facilitating reasoning [10]. In industrial practices, major information service enterprises such as Google, Yahoo and Microsoft have agreed on shared vocabularies with encoded semantics to publish the data on the Web [11]. This work surveyed existing industrial practices of knowledge management system developed using the ontological approach. We were, however, unable to find examples of best practice, which describe an empirical usage of knowledge management systems with a practical industrial dataset, to refer to for the development of the knowledge management system in our organization. However, it is understandable that industries treat their knowledge models and management systems as intellectual property [12] as they are important assets that help provide a competitive edge.

This paper introduces an ontology-based knowledge model and the core features of the proposed knowledge management system. The United Bible Societies want such a system to assist with information and service provision.

\section{The Knowledge Domain Context}

United Bible Societies (UBS) [13] is one of the world's largest Christian ministries. UBS is made up of 146 Bible Societies operating in more than 200 countries and territories. They translate, publish, and distribute the Bible, help people engage with content of the Bible, and are also active in areas such as literacy training, HIV/AIDS education and trauma healing. Bible Societies work in partnership and cooperation with all Christian churches and with some non-governmental organizations. Bible Societies' activity is expressed in over a thousand projects to facilitate the funding of these activities. A Global Mission Team (GMT) supports Bible Societies by helping them work together through consultation, coordination and the provision of shared services in areas such as international finance, project registration, capacity building, etc. The organizational structure of UBS is shown in Fig. 1. UBS is multi-cultural and multi-lingual, working in a geographically dispersed and collaborative way across the world - together these attributes make UBS a unique organization. 


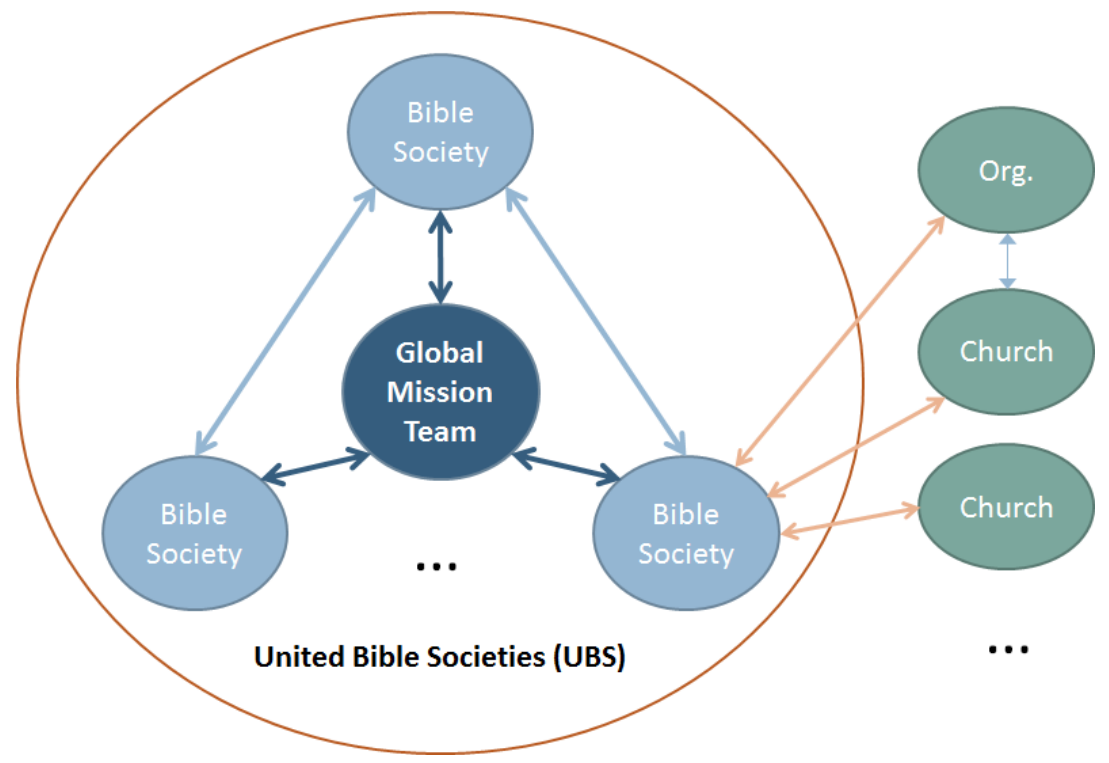

Fig. 1. The structure of the United Bible Societies

\section{Information and Information Sources}

This work analyzes the information systems in UBS. There include DBL (Digital Bible Library) system, UBS Community system, TMS (Translation Management System), Salesforce system, Project Registry system, and PSFinancials system. Fig. 2 shows the overview of the GMT core systems, and Table 1 shows a list of the existing information systems with the roles.

Each system is supporting Bible Societies in different domains. For example, DBL and TMS in the Bible domain, Project Registry in the Project domain, PSFinancials in the Financial domain, UBS Community in the Community domain, and HR.net and Salesforce in the Human resource domain. Currently, most of the data is searchable only vertically, which means that the information is only available within the domain [14]. Due to the independent design of the different systems, there is only limited syntactically integrated and shared data between the systems. As these systems evolve, it becomes increasingly difficult to extend and share the data. For example, Bible translation information in TMS system cannot be shared with the project information in the Project Registry system. Currently, the user needs to vertically search each domain manually to relate the search results from one domain to another. Integrating data syntactically, to enable a horizontal search to share the information between different domains, requires redesigning the system each time there is a need for new information sharing, and this does not allow for easy evolution. 


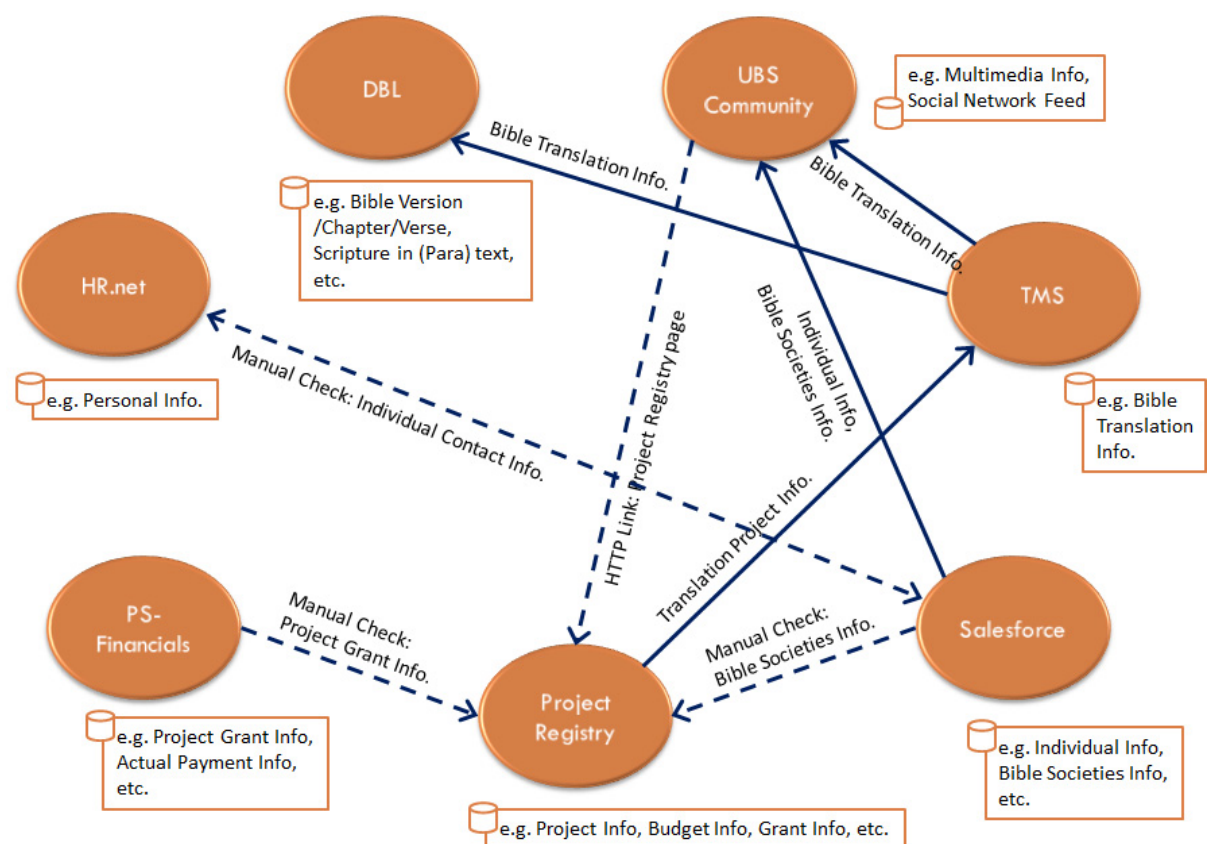

Fig. 2. Overview of GMT's core information systems

Table 1. List of GMT's core information systems and roles

\begin{tabular}{ll}
\hline System & Key Role \\
\hline Project Registry & Keeping track of projects in UBS \\
\hline PSFinancials & GFS (Global Financial Service) Project Ledger \\
\hline HR.net & Keeping Personal Information in GMT for Human Resource Management \\
\hline Salesforce & One central location for contact information of individual and Bible Societies \\
\hline DBL & A portal to allow people to access different Bible translations in one central location \\
\hline TMS & Keeping track of Bible translation projects in detail \\
\hline UBS Community & A portal for one contact point to access other systems in UBS \\
\hline
\end{tabular}

\section{Design of the Knowledge Management System}

Fig. 3 depicts the ontology-based knowledge management system (KMS) which enables creation of insights by processing the transactional data from the resources such as existing information systems. Each resource requires one plugin component, so when there is a need to import new resource, this can be handled by simply adding an additional plugin component. In this architecture, the system can easily evolve to incorporate the new imported information. 


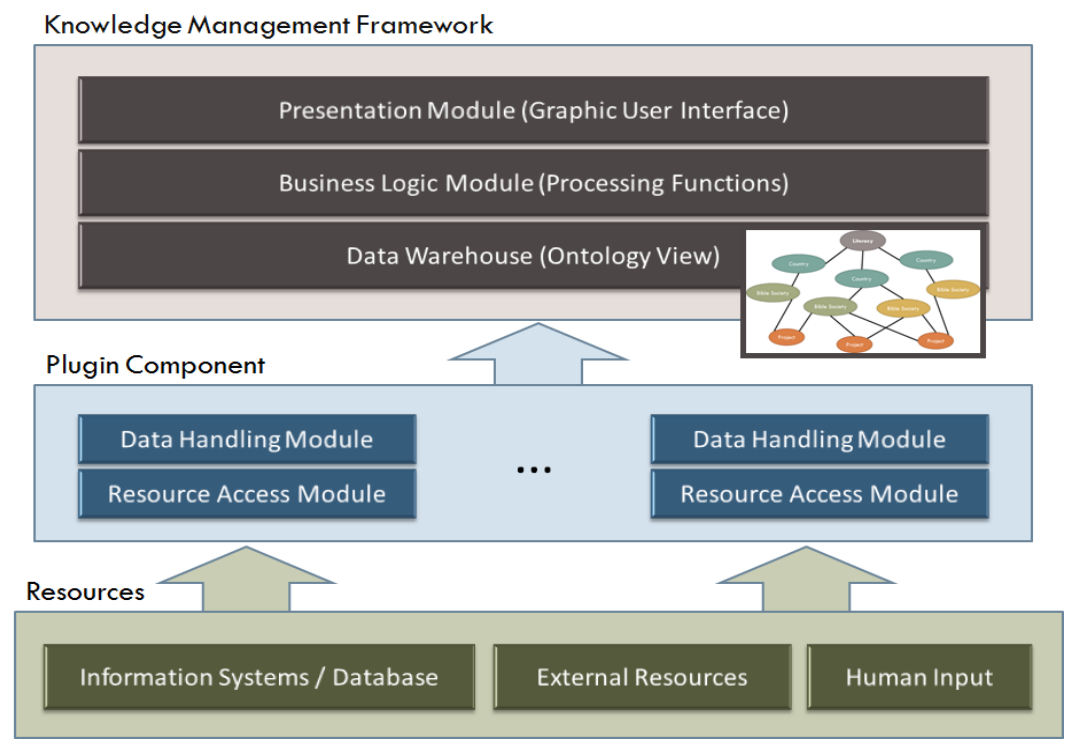

Fig. 3. The architecture of knowledge management system

The information from each domain will be aggregated and molded into the ontology model. This model dynamically generates the knowledge presentation to facilitate the discovery of new insight. Fig. 4 shows an example of the knowledge model developed to enable the sharing of information from different domains.

The requirements for the knowledge model for the UBS have been identified as followings.

\section{The model needs to import data from different sources:}

The ontology-based knowledge model can aggregate the information from different domains (even from outside the UBS domain, such as the CIA World Factbook [15] and UN Human Development Reports [16]) in one ontology knowledge model.

2. The model needs to keep relationships between entities:

The ontology-based knowledge model can formally describe the semantics of classes (general things in domains of interest), properties (attributes those things may have) and relationships that can exist among things [17].

3. The model needs to generate different knowledge presentations:

The ontology-based knowledge model can generate dynamically the knowledge presentations according to each entity defined in the ontology without altering the knowledge model [18].

4. The model needs to be applied by certain rules to enable the semantic search:

The ontology-based knowledge model can be semantically searched by query syntax such as SPARQL query [19] or SWRL rule [20]. For example, show Bible Societies making grants of more than $\$ 100,000$ to literacy projects which are implemented in Swahili-speaking countries in Africa. 


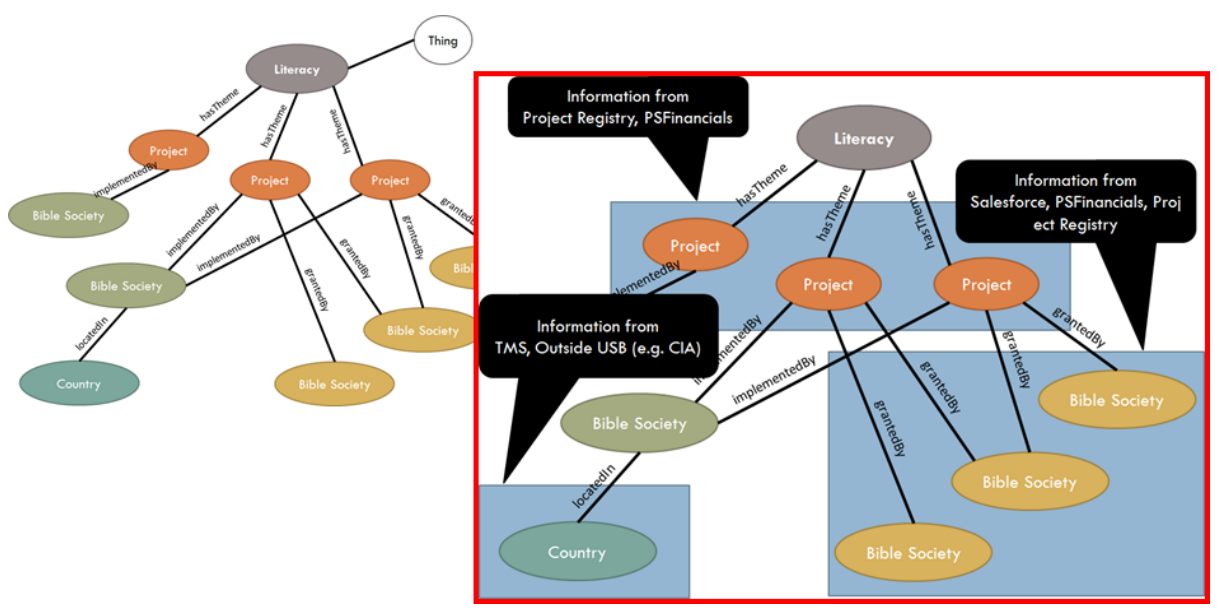

Fig. 4. The knowledge model using heterogeneous information resources

\section{$5 \quad$ Application of the Knowledge Model}

From the knowledge model we have proposed, the following interaction can be enabled, as an example. Fig. 5 shows the information details of each or group of entities in the model.

1. A Bible Society (BS) wants to make a funding grant to a literacy project. However, it does not know which projects or countries have the greatest needs.

2. The Knowledge Management System generates a literacy oriented knowledge presentation from the knowledge model. In the figure, Projects are the first information related to the literacy. The knowledge representation needs to be customized by user requirements. For example, Countries can be the first information to be related to the literacy if they are more appropriate for the user.
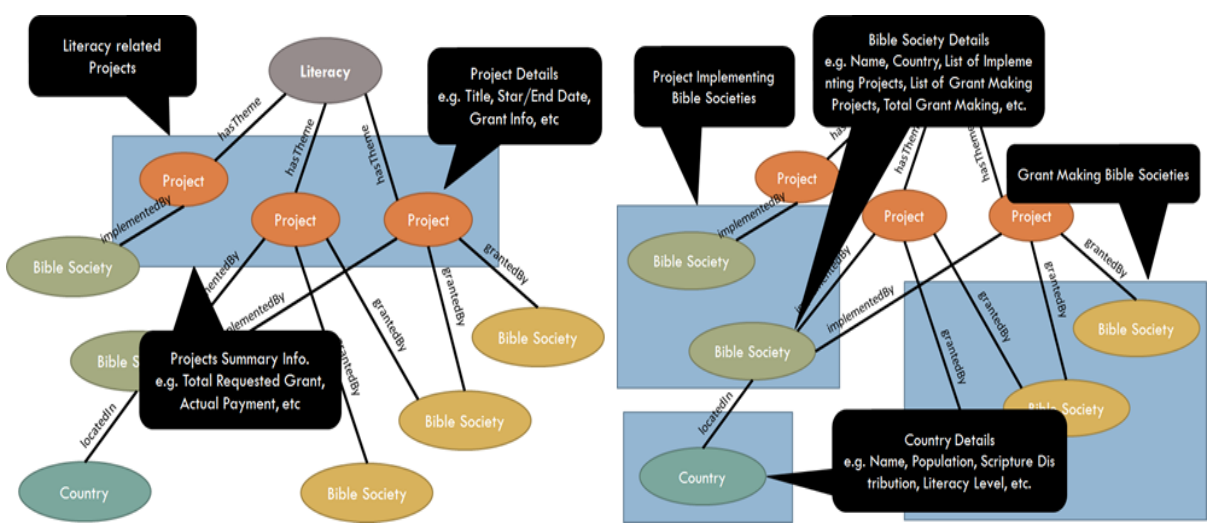

Fig. 5. The knowledge model using individual and group entities of information 
3. BS receives summary information (e.g. total grant requests/payments) of existing literacy projects and details of each project as shown in the left side of figure.

4. Country and Bible Society profiles (e.g. literacy rate and population) are presented along with the projects as shown in the right side of figure.

5. BS discovers which projects require the most support, and decides to make grants to certain projects.

\section{Conclusion}

This paper has described the process of developing a Knowledge Management System (KMS) in UBS that takes the ontological approach, using an ontology-based knowledge model. This model aims to enable horizontal searches, not just vertical searches within a domain, and information sharing between different data sources in different domains. The KMS, using an ontology-based knowledge model, will shape the information into knowledge by aggregating, molding, linking and reasoning with the data. This will facilitate the discovery of new insights by revealing implicit information, which could be hidden without applying semantics to the data.

For the future work, we will further design the technical functions in the KMS and deploy the KMS in the day-to-day operations of UBS. Rigorous data collection and processing will be undertaken, followed by rigorous validation of the knowledge model. A successful implementation will also require the consideration of issues related to user motivation and change management.

Acknowledgement. The development of the knowledge management system is partially funded by Technology Strategy Board (TSB) (KTP009100-508802) and supported by University of Reading.

\section{References}

1. Havens, C.T.: Knowledge management system and method, U.S. Patent and Trademark Office, U.S. Patent No. 5,924,072, Washington, DC (July 13, 1999)

2. Rho, S., Park, J.: Ontology: The key of Internet Evolution, from Web 2.0 to Web 3.0, Gods'Toy Business, Korea, ch. 1 (2007) ISBN13-9788995919118

3. Davenport, T.H.: Saving IT's Soul: Human-Centered Information Management. Harvard Business Review 72(2), 119-131 (1994)

4. Madhavan, J., Jeffery, S., Cohen, S., Dong, X., Ko, D., Yu, C., Halevy, A.: Web-scale Data Integration: You can only afford to pay as you go. In: Proceedings of CIDR, pp. 342-350 (2007)

5. Chai, X., Sayyadian, M., Doan, A., Rosenthal, A., Seligman, L.: Analyzing and Revising Data Integration Schemas to improve their matchability. Proceedings of the VLDB Endowment 1(1), 773-784 (2008)

6. Bernstein, P.A., Haas, L.M.: Information Integration in the Enterprise. Communications of the ACM 51(9) (2008) 
7. Waters, J., Powers, B.J., Ceruti, M.G.: Global Interoperability Using Semantics, Standards, Science and Technology (GIS3T). J. Computer Stands and Interfaces 31(6), 1158-1166 (2009)

8. Antoniou, G., Harmelen, F.V.: Web Ontology Language: OWL. In: Handbook on Ontologies, pp. 67-92. Springer, Heidelberg (2004)

9. Noy, N.F.: Semantic Integration: a survey of ontology-based approaches. ACM Sigmod Record 33(4), 65-70 (2004)

10. Gardner, S.P.: Ontologies and Semantic Data Integration. Drug Discovery Today 10(14), 1001-1007 (2005)

11. Schema RDFS Organization, Linked Data Community: Supporting Schema.org deployment and usage with a special focus on Linked Data (2011),

http: / /schema.rdfs.org/

12. Castle, D., et al.: Knowledge Management and the Contextualisation of Intellectual Property Rights in Innovation Systems. Journal of Law, Technology and Society 7(1), 32-50 (2010)

13. The United Bible Societies, Swindon, UK (2014), http: / /www . unitedbiblesocieties.org/

14. Shettar, R., Bhuptani, R.: A Vertical Search Engine-Based On Domain Classifier. International Journal of Computer Science and Security 2(4), 18-27 (2007)

15. The World Factbook by Central Intelligence Agency, Washington DC, US (2013), https: / / www.cia.gov/library/publications / the-world-factbook/index.html

16. Human Development Reports by United Nations Development Programme (2012), http: / / har. undp.org/en/data

17. World Wide Web Consortium (W3C), OWL Web Ontology Language Use Cases and Requirements, W3C Recommendation (2004), http: / /www . w3 . org / TR/ webont-req/

18. Katifori, A., Halatsis, C., Lepouras, G., Vassilakis, C., Giannopoulou, E.: Ontology Visualization Methods - A Survey. ACM Computing Surveys (CSUR) 39(4), 10 (2007)

19. World Wide Web Consortium (W3C), SPARQL Query Language for RDF, W3C Recommendation (2008), http: / / www.w3 . org/TR/rdf-sparql-query/

20. World Wide Web Consortium (W3C), SWRL: A Semantic Web Rule Language Combining OWL and RuleML, W3C Recommendation (2004), http: / / www.w3 .org/Submission/SWRL/ 